\title{
Changing route: Common action on food systems transformation in the Mediterranean
}

\author{
Roberto Ridolfi, Sandro Dernini*, Jamie Morrison*, \\ Árni M. Mathiesen*, Roberto Capone**
}

DOI: $10.30682 / \mathrm{nm} 2003 \mathrm{~h}$

JEL codes: O13, Q11, Q18

\begin{abstract}
The Coronavirus pandemic has revealed the fragility of our food systems, affecting all dimensions of food security and nutrition across the world. It has highlighted how deeply our world is interconnected and the importance of better recognising and understanding the interconnections that are intrinsic to these systems and their key role in pursuit of the SDGs of the 2030 Agenda. There is now, more than ever, a stronger need for a "route change" towards a common action on food systems transformation. Dialogues among all stakeholders to redesign the future of tomorrow's food systems are needed to trigger collective, multi-stakeholder actions on the ground, at local, regional and global level, towards more sustainable food systems, linking sustainable food production to more healthy and sustainable food consumption. In this context CIHEAM, FAO, and the Union for the Mediterranean Secretariat (UfMS) initiated in 2019, a joint collaborative effort for the establishment of a multi-stakeholder platform on Sustainable Food Systems in the Mediterranean to accelerate the shift towards the Agenda 2030 in the Mediterranean region, with the Mediterranean diet acting as a driver.
\end{abstract}

Keywords: Food systems transformation, COVID-19, Sustainable food systems, Mediterranean diet, Sustainable diets, Sustainable food consumption and production, Multistakeholder approaches, Agenda 2030, SDGs, Mediterranean region.

The Coronavirus pandemic has revealed the fragility of our food systems to shocks, fragilities that are particularly damaging the most vulnerable populations. The COVID-19 pandemic is affecting food systems and all dimensions of food security across the world. At the G20 Extraordinary Virtual Leaders' Summit on COVID-19, on March 26, 2020, the FAO Director-General QU Dongyu urged leaders from the G20 countries to take measures to ensure that global food systems continue to work well, particularly in relation to access to food for the world's poor and most vulnerable during the COVID-19 pandemic.
Today, over 820 million people are hungry, with the recently published report on food crisis (FSIN, 2020) suggesting that a further deterioration is expected in 2020. At the same time, a substantial proportion of all food produced is either lost or wasted, and more than 2 billion people are overweight or obese. As stressed in its preface by the UN Secretary-General António Guterres, "the number of people battling acute hunger and suffering from malnutrition is on the rise yet again. In many places, we still lack the ability to collect reliable and timely data to truly know the magnitude and severity of food crises

\footnotetext{
* FAO, Rome, Italy.

** CIHEAM - Istituto Agronomico Mediterraneo di Bari, Valenzano, Italy.

Corresponding author: dernini@iamb.it
} 
gripping vulnerable populations. And the upheaval that has been set in motion by the COVID-19 pandemic may push even more families and communities into deeper distress."

Food systems are not just failing to deliver on the goal of eliminating hunger. They are also holding back progress towards a number of other SDGs. They contribute up to 29 per cent of all GHG emissions, including 44 per cent of methane, significantly contributing to climate change. Agriculture is also responsible for up to 80 per cent of biodiversity loss, for up to 70 per cent of all freshwater use and 80 per cent of all deforestation, and more than one-quarter of the energy used globally is expended on food production and supply (UN, 2019).

FAO estimated that to satisfy the needs of a growing and richer population with an increased demand for animal products, food production will have to increase by 60 percent towards 2050 (Alexandratos and Bruinsma, 2012).

Agro-food systems need to grow within the context of a finite and sometimes shrinking resource base, and must use natural resources in a sustainable manner to preserve the ecosystems on which they rely. Such growth needs to be inclusive and target broader objectives other than just primary production; it must improve efficiencies throughout the food system, from production to consumption, to promote sustainable practices and diets, within a coherent cultural and social framework. Unless food consumption and production patterns are better aligned, and within planetary boundaries, such pressures will increase further (FAO, 2012).

The big question today is whether the food systems in their present form are sustainable and will provide a reliable cornerstone to guarantee the future of the Human System as a whole. The rights of individuals including the right to food and nutrition need to be respected.

\section{The need for a radical change in food systems transformation}

Changing course is critical - "business as usual" is no longer an option. If food and agricultural systems remain on their current path, the evidence points to a future characterized by persistent food insecurity and unsustainable economic growth (FAO, 2018a).

In light of the new challenges posed by the ongoing and unprecedented COVID-19 crisis, which is putting further strain on food supply chains, there is now, more than ever, a stronger need for a "route change" towards a common action on food systems transformation. The COVID-19 pandemic has highlighted how deeply our world is interconnected and the importance of better recognising and understanding the interconnections that are intrinsic to these systems and their key role in pursuit of the SDGs of the 2030 Agenda. The diagram below provides a snapshot of how COVID-19 might impede each of the SDGs.

The COVID-19 crisis is an opportunity to accelerate a radical change of route. The pandemic is an opportunity to hit the reset button, with scientists and social scientists playing an important part (Torero, 2020). The complexity of global challenges can only be managed through collective multistakeholder actions to foster more sustainable food systems that are resilient to the impacts of full-blown crises. Global commitment for a shift towards more sustainable food systems, as reflected in the United Nations One Planet Network SFS Programme, ${ }^{1}$ has already increased significantly in the international community over

1 UN One Planet Network SFS Programme has the goal to accelerate the shift towards more sustainable food systems, now has 172 members, with a portfolio of 54 initiatives and four task forces. It has been increasingly acknowledged as an important multi-stakeholder partnership for the promotion of sustainable food systems. The HLPF 2018 Ministerial Declaration recognized the One Planet Network as an implementing mechanism for the SDGs and "called upon all stakeholders to adopt a food systems approach". At the $4^{\text {th }}$ United Nations Environment Assembly in March 2019, Ministers pledged "to promote sustainable food systems", and a resolution on reducing food loss and waste was adopted with explicit links to the SFS Programme. In June 2019, the FAO Conference endorsed the recommendations of FAO's Committee on Agriculture, including to "support governments, upon request, in adopting a sustainable food systems approach" and to "continue its support in strengthening strategic partnerships and platforms, notably the 10YFP Sustainable Food Systems Programme (currently named One Planet Network SFS Programme)". https://www. oneplanetnetwork.org/sustainable-food-system. 
Figure 1 - COVID-19 and impacts on SDGs.

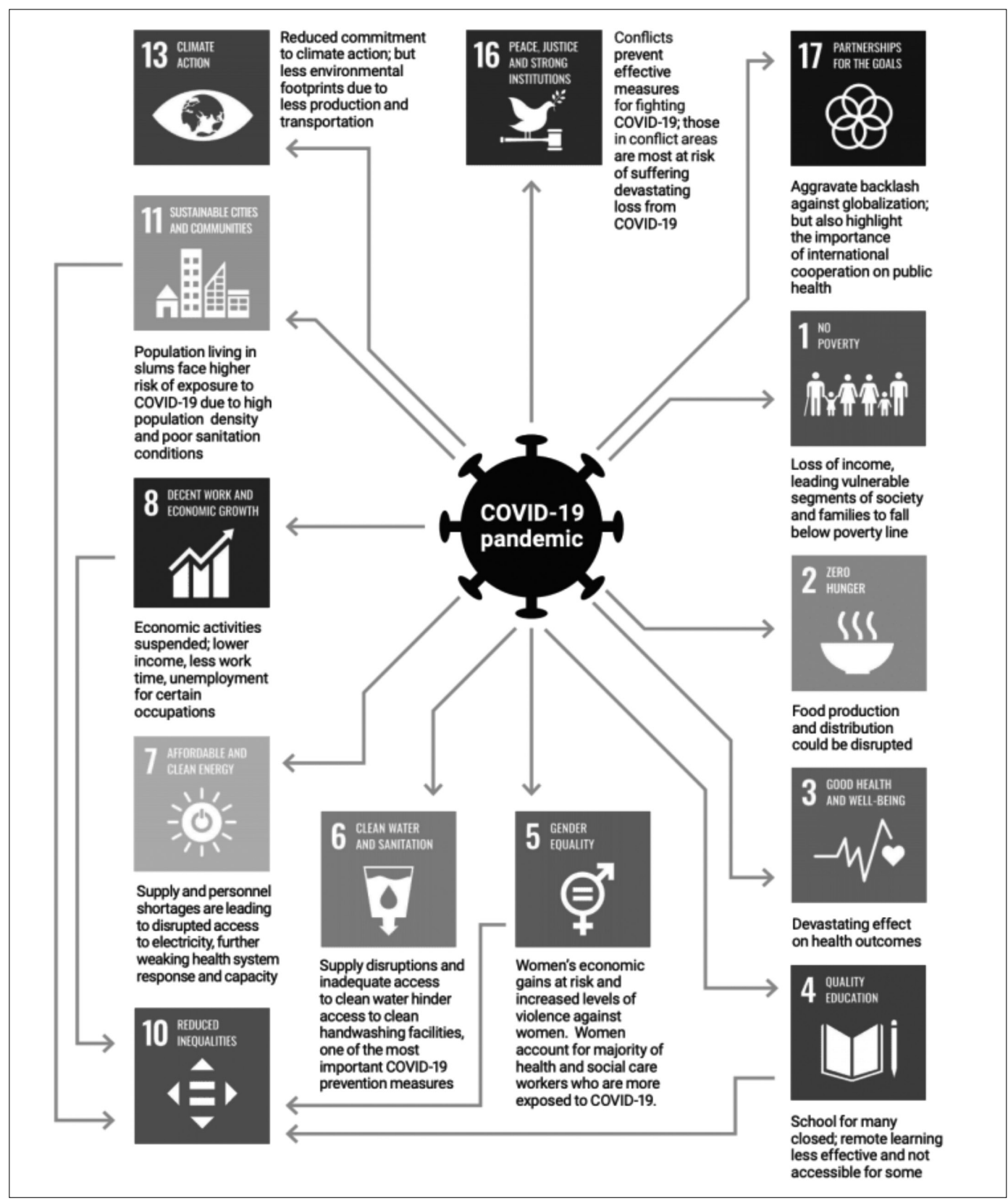

Source: UNDESA 2020.

the recent years, supporting this transformational change, as part of the collective efforts for achieving the ambitious goals of the 2030 Agenda.

The UN Food Systems Summit, to be convened by the Secretary-General in 2021, as part of the Decade of Action and with the aim of maximizing the co-benefits of a food systems approach across the entire 2030 Agenda, will be a great opportunity to raise the importance of food systems transformation to the highest level, affirming its centrality to the achievement of the majority of the SDGs. 


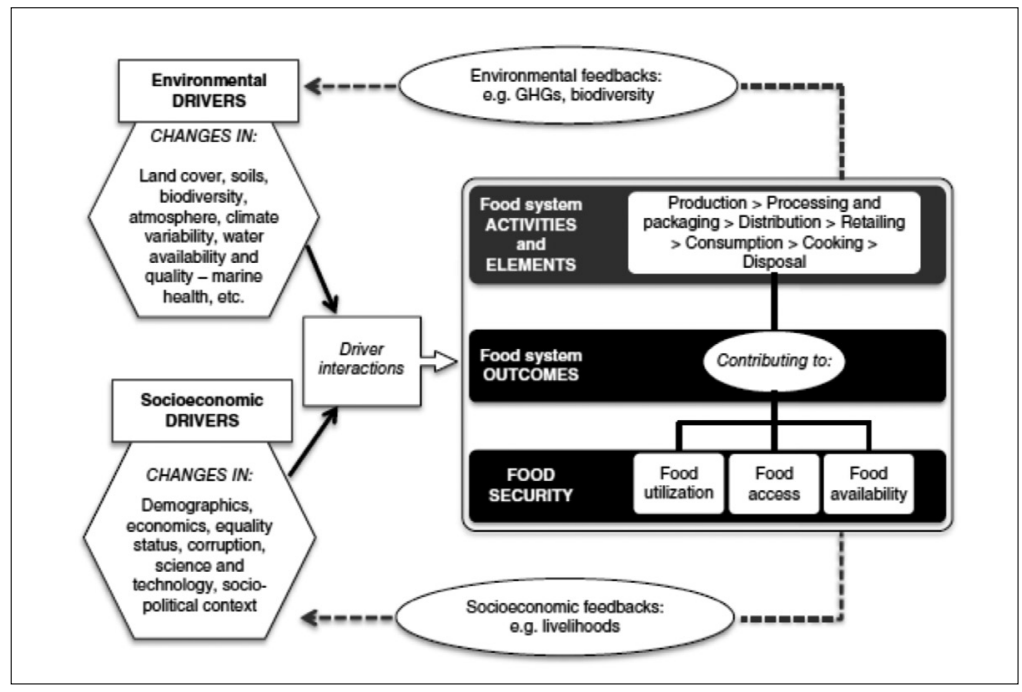

Figure 2 - Food Systems Interactions and Feedback Loops.

Source: Mulet et al., 2019.

The 2030 Agenda marks a significant shift from traditional development approaches by recognizing the important role the private sector has to play in achieving sustainable development for all. Financing the realization of all SDGs will require additional annual investments of approximately 2.5 trillion USD! Even a dramatic increase in official development assistance will not be sufficient to close this investment gap, and it is thus essential to engage the mainstream private sector sustainably and to ensure that private investments be SDG-compliant or aligned. The transformation of food systems is key to achieving many SDGs (Ridolfi, 2019).

A recent conference of the Group of Friends of Food Security and Nutrition took place on 17 April 2020 and built the clear link between the post COVID-19 recovery and the UN Food Systems Summit in 2021. The Joint Statement looks towards the Food Systems Summit, which "provides a timely opportunity for all food systems actors to strengthen the resilience and sustainability of our food systems to help galvanize the post-emergency recovery through a set of initia- tives focused on innovation, financing, technology, partnerships and new levels of regional and global collaboration and information sharing."

There is indeed a need for a better understanding of links between a sustainable food system, the health status of the population, the cost to government budgets of the unsustainability of food systems, as well as the cost of depleting biodiversity, excessive water consumption and unacceptable levels of climate changing emissions. Dialogues among all stakeholders to redesign the future of tomorrow's food systems are needed to trigger collective, multi-stakeholder actions on the ground, at local, regional and global level, towards more sustainable food systems, by linking sustainable food production to more sustainable food consumption.

Tackling concretely food system transformation is a very complex and lengthy process. Therefore, a change of route towards an integrated systemic approach to food system transformation is needed, to avoid narrow technical fixes of certain constraints throughout the food system while recognizing trade-offs which countries are facing in coping with different challeng-

2 These and other concerns were expressed during an extraordinary video conference that took place on 17 April 2020, under the auspices of the Group of Friends of Food Security and Nutrition. The conference brought together over 270 participants from across the UN and its Member States to discuss actions to mitigate the potential socio-economic impacts of COVID-19 on food availability and supply, and to attain food security. The conference was convened by: Emanuela Claudia Del Re, Italy's Vice Minister of Foreign Affairs, as Chair of the Group of Friends of Food Security and Nutrition in New York. 
es and when trying to achieve multiple results. In all countries, decision-making affecting the evolution of food systems is very fragmented, and new forms of innovative multi-stakeholder strategies and transdisciplinary knowledge sharing are urgently required. Never before has it been so important to focus collective energy and collaborative efforts on promoting resilient, sustainable food systems (HLPE, 2020).

There is a need for more transdisciplinary systemic approaches, with science-based evidence for validating assumptions on the benefits of sustainable food systems, and their trade-offs, in different contexts.

A key challenge is to identify interlinkages between the SDGs using a metric of measurements through the SDGs indicators, that accounts for different development processes drivers and trade-offs and how they can have a positive impact on every stage of food systems (production, processing, distribution, sale, consumption including food losses and waste).

FAO being custodian of more than 21 indicators for the SDGs is in the position to adapt the scientific approach to the concrete, practical needs of business in order to add to the policy action by governments, the investment push by private companies, the financial sector and the consumers' groups. FAO SDG-compliant tools will concretely support food systems transformation to pursue the SDGs achievement.

\section{Can the COVID-19 crisis help to accelerate the food systems transformation?}

The entire food system is touched by the impacts of the COVID-19 pandemic, from primary supply, to processing, to trade as well as national and international logistics systems, to intermediate and final demand (Schmidhuber et al., 2020).

A challenge will be to build on, and sustain some of the potentially positive adaptations that we are seeing towards re-localization and re-engagement with food, while mitigating against some possibly negative developments such as greater reliance on longer shelf life products, and significant reductions in demand for higher value products focused on export markets, which could hit some sectors particularly hard. In addition, we also need to recognize that we may still only be in the early stages of a deeper economic crisis. Questions triggered by the crisis will however remain valid for the post crisis:

Will consumers and the larger distributors look for food on the shelf with longer life span? Is this going to affect the way we perceive the role of fresh fruits and vegetables seen as a part of a healthier diet?

While shorter supply chains can be more resilient to shocks of the magnitude of the virus, is a shift in this direction compatible with efficient globalised food systems, mainly operating through commodities crossing borders? Where is the balance?

While, the private sector will be a key stakeholder in designing and delivering scalable and practical solutions for food systems transformation, that advance food security, protect the environment and ensure economic opportunities by increasing resilience and sustainability, the impact of COVID-19 on food security and nutrition also highlights the importance of strengthening governments' role in protecting marginalized populations who have less power and resources to adapt to crisis, and already have difficulty accessing nutritious foods. At the G20-Argentina, in 2018, within the session on "Redirecting investment for a global food system that is sustainable and promotes healthy diets", the need for more and better quality private sector investment in food systems for the achievement of the SDGs was strongly underscored. By taking into consideration how recent developments in food systems have resulted in new challenges and controversies, both with respect to their sustainability, and the extent to which they are contributing to diets that are more nutritious, the key challenge was how to redirect investment such that it is both adequate to drive dynamic food systems development and has the quality of promoting inclusive and sustainable systems. This challenging issue was addressed through three areas of action: instruments that translate growing consumer awareness into SDG compliant investment; instruments that encourage investment in food systems in high risk contexts; and improve- 
ments to food system governance (Morrison et al., 2018). All three actions are closely related to the Mediterranean region context.

\section{The Mediterranean as a region ripe for a transformation towards more sustainable food systems}

The Mediterranean region, around mare nostrum, at the crossroads between the African, Asian and European continents is facing unprecedented and interdependent health/nutritional, environmental, economic and socio-cultural challenges that affect food security, nutrition and sustainability of all countries (CIHEAM/FAO, 2015).

To deliver more sustainable food systems in the Mediterranean region, new forms of innovative multi-stakeholder joint strategies and transdisciplinary knowledge sharing dialogues are foreseen as necessary between the Northern and the Eastern/Southern shores, where there is a stronger need of scientific research and data for impacts assessment, as well as capacity building and innovation.

CIHEAM, FAO, and the Union for the Mediterranean Secretariat (UfMS) initiated in 2019 a joint collaborative effort, inclusive of all interested stakeholders, towards the establishment of a multi-stakeholder platform on Sustainable Food Systems in the Mediterranean (the SFS MED Platform). ${ }^{3}$ The Platform offers a unique opportunity for piloting and validating a "change of route", and tracking its navigation towards food systems transformation in the region. It will bring together different mandates for mobilizing stronger partnerships towards more resilient sustainable food systems in the Mediterranean.

The SFS MED Platform, by taking into account the differences of food systems in the Mediterranean region, on both Northern and Eastern/Southern shores, will foster a better understanding of the interconnections between individual SDGs and the multi-dimensional na- ture of the food sustainability through a holistic systemic approach, context-specific for the Mediterranean, in response to the multiple and interconnected challenges the Mediterranean countries are facing today.

In all Mediterranean countries, decision-making affecting the evolution of food systems is very fragmented. One of the main challenges that food system transformation faces is a very limited understanding not only of the performance of food systems but also of the trade-offs between the different objectives, SDGs and associated targets to be achieved through food systems interventions and transformation.

There is a strong need for scientific evidence including greater availability of local data, in the context of the assessment of food systems sustainability, and in providing a sound scientific basis for actions towards more sustainable food system.

\section{The Mediterranean diet: a formidable driver}

The Mediterranean is currently seen mostly as a dividing sea between the two shores, however history tells otherwise. Culturally diverse countries are still united within the Mediterranean diet heritage, acknowledged in 2010 by UNES$\mathrm{CO}$ as an intangible cultural heritage of Humankind (UNESCO, 2010).

The Mediterranean diet, as an expression of the diversity of Mediterranean food cultures and their different food production, processing and culinary systems, has not yet been recognized as a resource for promoting sustainable development in the Mediterranean region (Lepellere et al., 2019).

Data show a decline in adherence to the Mediterranean dietary pattern in all Mediterranean countries (da Silva et al., 2009; Vareiro et al., 2009). All Mediterranean countries are passing through a "nutrition transition" in which under-nutrition problems (wasting, stunting,

\footnotetext{
3 The process for the establishment of the SFS MED Platform is conceived as a tripartite effort, inclusive of all interested stakeholders, triggered at the $2^{\circ}$ World Conference on the Revitalization of the Mediterranean Diet on "Strategies towards More Sustainable Food Systems in The Mediterranean Region. The Mediterranean Diet as a Lever for Bridging Consumption snd Production in a Sustainable and Healthy Way", held in Palermo, in May 2019. https:/www.iamb.it/uploads/attachments/954/Palermo_Conference_Summary_Report_1_.pdf.
} 
Figure 3 - The multiple sustainable benefits of the Mediterranean diet.

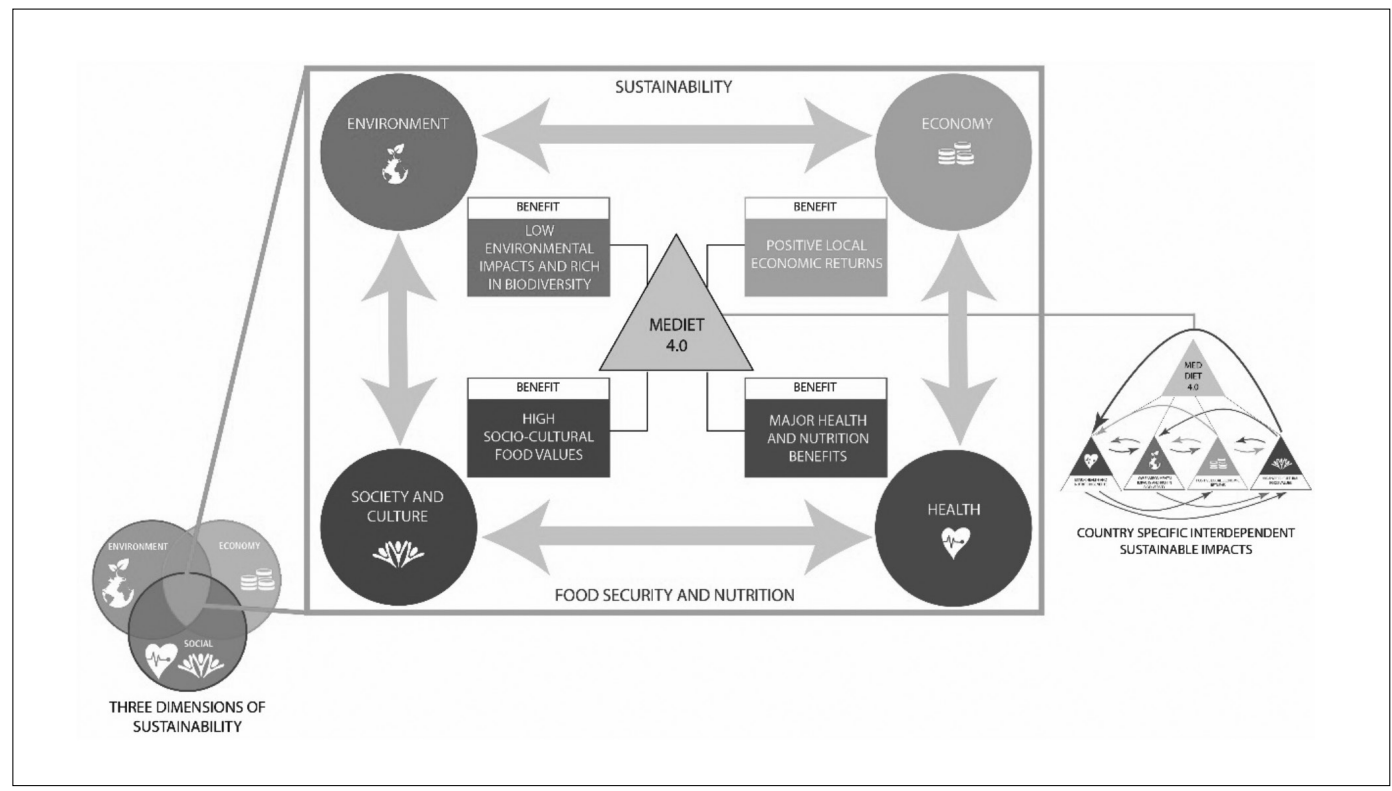

Source: adapted from Dernini et al., 2017.

underweight) and micronutrient deficiencies coexist with over-nutrition problems (overweight, obesity) and diet-related chronic non-communicable diseases (Aounallah-Skhiri et al., 2011; Belahsen, 2014; Nasreddine et al., 2018). This growing nutrition transition in the Mediterranean which is leading to a "triple burden of malnutrition" is alarming as it has a negative impact not only on health but also on food systems (CIHEAM/FAO, 2015).

Therefore, there is a need for a change of route to revitalize the Mediterranean diet, as a lever to linking sustainable food consumption and production, a precondition for sustainable Mediterranean food systems. The diversity and variety of the food characteristics of the Mediterranean diet, if valorised, can drive a variety of demands, therefore influencing food production supportive of greater biodiversity: this is the extraordinary essence of the Mediterranean region.

In recent years within the international debate on the sustainability of food systems, the interest for the Mediterranean diet, acknowledged as one of the healthiest diets in the world, has started to be analysed by CIHEAM and FAO (Burlingame and Dernini, 2012; Dernini et al., 2013), as a dietary pattern with multiple sustainability benefits and country-specific variations: 1) Recognized and well-documented major health and nutrition benefits, in the prevention of chronic diseases and in reducing public health costs as well as in the overall improvement of well-being; 2) Low environmental impacts and richness in biodiversity, appreciation of biodiversity value, reduction of pressure on natural resources and mitigation of climate change; 3 ) High positive local economic returns, sustainable territorial development, reduction of rural poverty, and high performance in reduction of food waste and loss; 4) High social and cultural value of food, growth of mutual respect, identity recovery, social inclusion and consumer empowerment (Dernini et al., 2017).

\section{From Blue Growth to Green and Circular Economy as key for a food systems transformation towards sustainability in the Mediterranean}

The Mediterranean sea is the main element bridging all countries facing it as well as their different food systems. Today around ten per- 


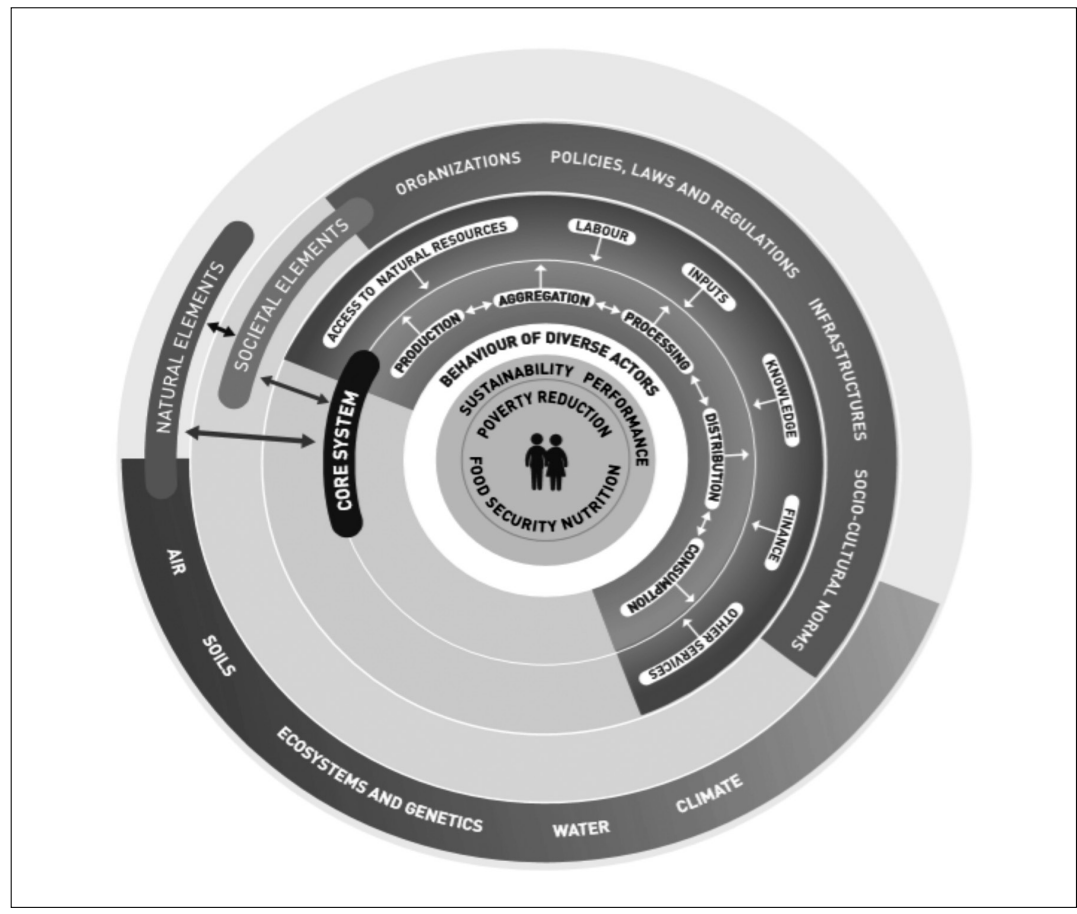

Figure 4 - The Food System Wheel.

Source: FAO, $2018 a$.

cent of the global population relies on fisheries and aquaculture for their livelihoods, but the very large majority of the total number of people involved in fisheries are some of the poorest and most vulnerable in the world.

The SFS MED Platform intends to address this situation by bringing in blue growth at the core. It is extremely important, both for the individuals and for the communities concerned, as well as for the success of the fisheries improvement, that new jobs be created.

There is also a need to acknowledge old environmental problems such as biodiversity hazards and land-based oceanic pollution, co-exist with new ones like plastic and other pollutants and climate change. Therefore, there is a need to put "all our efforts" and appropriate resources, both technical and socio-economic, into coping with and solving these challenges. Using both old and new methods and not forgetting the old ones just because we have new ones. In fact the old ones can be just as appropriate, and maybe more so, under various circumstances and stages of development, for the benefit of a larger part of the global population (Mathiesen, 2019).

More green, blue and circular economy is at the core of SFS MED food systems transformation for driving more sustainable development in the region and a better quality of livehoods for all. It is paramount to safeguard the position of farmers and fishers in the value chain, to promote "green" and "blue" growth, as well as a circular economy, and to encourage sustainable food consumption and ensure affordable and healthy food for all.

The adoption of sustainable consumption and production patterns (SCP) as a means of achieving a Green Economy and Blue Growth has been recognized as an integral part of the 2030 Agenda. ${ }^{4}$ Sustainable food systems are also among the key elements of the European Green Deal, which cannot be achieved without addressing the issue of food sustainability, as underscored in the EU Farm to Fork Strategy.

\footnotetext{
${ }^{4}$ http://wedocs.unep.org/bitstream/handle/20.500.11822/28463/K1901029.pdf?sequence=6\&isAllowed=y.
} 


\section{Conclusions}

Global and local coordination are essential in our fragile planetary environment, to ensure that the outcomes of all initiatives and actions are sustainable, resilient and in line with the SDGs.

Global challenges can be better managed through collective multistakeholder actions towards more resilient and sustainable food systems that also can prevent or mitigate fullblown crises. Food systems are at the centre of many challenges facing the international community. These challenges are all interrelated and require a SFS context-specific approach, for each sector and each country to find their own appropriate solutions.

Moreover, food systems worldwide are becoming increasingly interconnected, through global, regional and local markets and supply chains, and, therefore, there is a need to identify the interlinkages between the SDGs, development challenges, drivers, processes, outcomes and tradeoffs and how they can have a positive impact on every stage of food systems (production, processing, distribution, sale, consumption).

Current challenges need to be tackled through a renewed innovative vision of a "change of route", on sustainable food systems transformation that requires linking sustainable consumption and production (SCP), at diverse scales. Hence, with the focus on people, there is a need to better understand food-related choices and drivers as related to their cultural, social, economic and environmental circumstances.

The complexity of interdependent challenges, requires a rethinking on new forms of collaborative transdisciplinary exchanges, science-based evidences and multistakeholder partnerships, and local knowledge-sharing, towards sustainable food systems transformation in different challenging contexts, such as the Mediterranean region.

Member States, academia, civil society organisations and the private sector will be key in crafting, built on "knowledge", the solution via more sustainable food systems (SFS) in the Mediterranean region, with the Mediterranean diet acting as a driver, connecting the nutritional well-being of the individual and the community to the sustainability of natural resources, and reaffirming the notion that the health of humans cannot be isolated from the health of ecosystems (Berry et al., 2015).

\section{References}

Alexandratos N., Bruinsma J., 2012. World agriculture towards 2030/2050: The 2012 revision. ESA Working Paper 12-03. Rome: FAO.

Aounallah-Skhiri H., Traissac P., El Ati J., Eymard-Duvernay S., Landais E., Achour N., Delpeuch F., Romdhane H.B., Maire B., 2011. Nutrition transition among adolescents of a south-Mediterranean country: dietary patterns, association with socio-economic factors, overweight and blood pressure. A cross-sectional study in Tunisia. Nutrition journal, 10(1): 38 .

Belahsen R., 2014. Cultural diversity of sustainable diets. Nutrition transition and food sustainability. Proc Nutr Soc, 73(3): 385-388.

Berry E.M., Dernini S., Burlingame B., Meybeck A., Conforti P., 2015. Food security and sustainability: can one exist without the other? Public Health Nutr, 18(13): 2293-2302.

Burlingame B., Dernini S. (eds.), 2012. Sustainable diets and biodiversity. Directions and solutions for policy, research and action. Rome: FAO.

CIHEAM/FAO, 2015. Mediterranean food consumption patterns: diet, environment, society, economy and health. A White Paper Priority 5 of the Expo Milan 2015 Feeding Knowledge Programme. Bari: CIHEAM; Rome: FAO.

Da Silva R., Bach-Faig A., Raido Quintana B., Buckland G., Vaz de Almeida M.D., Serra-Majem L., 2009. World variation of adherence to the Mediterranean diet, in 1961-1965 and 2000-2003. Public Health Nutr, 12(9A): 1676-1684.

Dernini S., Berry E.M., Serra-Majem L., La Vecchia C., Capone R., Medina F.X., Aranceta-Bartrina J., Belahsen R., Burlingame B., Calabrese G., Corella D., Donini LM., Lairon D., Meybeck M., Pekcan A.G., Piscopo S., Yngve A., Trichopoulou A., 2017. Med Diet 4.0: the Mediterranean diet with four sustainable benefits. Public Health Nutr, 20(7): 1322-1330.

Dernini S., Meybeck A., Burlingame B., Gitz V., Lacirignola C., Debs P., Capone R., El Bilali H., 2013. Developing a methodological approach for assessing the sustainability of the sustainability of diets: The Mediterranean diet as a case study. New Medit, 12(3): 28-36.

FAO, 2018a. The future of food and agriculture - Alternative pathways to 2050. Rome: FAO. 
FAO, 2018b. Sustainable Food Systems, Concept and framework. Rome: FAO.

FAO, 2012. Improving food systems for sustainable diets in a green economy. Working Paper 4: Utilization. In: Greening the economy with agriculture. Rome, FAO, pp. 185-241.

FSIN (Food Security Information Network), 2020. Global report on food crises: Joint analysis for better decisions. Fourth Annual Global Report on Food Crises (GRFC 2020). Rome, Washington DC: FAO, WFP, IFPRI.

HLPE, 2020. The impact of COVID-19 on food security and nutrition. Interim issues paper by the High-Level Panel of Experts on Food Security and Nutrition (HLPE). Rome: CFS.

Lepellere M.A., Chang T.F., Droli M., Iseppi L., 2019. The hidden turning points of the Mediterranean diet: a tool for health and agro-food policies. Rating out of fifty years, and 22 countries. New Medit, 18(2): 71-88. http://dx.doi.org/10.30682/nm1902e.

Mathiesen A.M., 2019. The Industrial Revolution, Blue Growth and Development Policies. New Medit, 18(2): 133-136.

Morrison J., Bianchi E., Bowyer C., Vos R., Wellesley L., 2018. Redirecting investment for a global food system that is sustainable and promotes healthy diets. Food Security and Sustainable Development. T20-Argentina. https://t20argentina. org/publicacion/redirecting-investment-for-aglobal-food-system-that-is-sustainable-and-promotes-healthy-diets/.

Mulet M., Mink P., Dernini S., Bortoletti M., Lomax J., 2019. The 10YFP Sustainable Food Systems
(SFS) Programme as a multi-stakeholder platform for a systemic approach. In: Burlingame B., Dernini S. (eds.), Sustainable diets: Linking nutrition and food systems. Boston: CABI, pp. 178-186.

Nasreddine L.M., Kassis A.N., Ayoub J.J., Naja F.A., Hwalla N.C., 2018. Nutritional status and dietary intakes of children amid the nutrition transition: the case of the Eastern Mediterranean Region. Nutrition research, 57: 12-27.

Ridolfi R., 2019. SDGs for people, planet, and prosperity. FAO's SDG compliance work as a means for leveraging sustainable investments in agri-food systems. Rome: FAO.

Schmidhuber J., Pound J., Qiao B., 2020. COVID-19: Channels of transmission to food and agriculture. Rome: FAO. https://doi.org/10.4060/ca8430en.

Torero M., 2020. Without food, there can be no exit from the pandemic. Nature, 580: 588-589.

Vareiro D., Bach-Faig A., Raidó Quintana B., Bertomeu I., Buckland G., Vaz de Almeida M.D., Serra-Majem L., 2009. Availability of Mediterranean and non-Mediterranean foods during the last four decades: comparison of several geographical areas. Public Health Nutr, 12(9A): 1667-1675.

UN, 2019. Global Sustainable Development Report 2019: The Future is Now - Science for Achieving Sustainable Development. New York: United Nations.

UNESCO, 2010. Inscription of Mediterranean diet on the Representative List of the Intangible Cultural Heritage of Humanity. Intergovernmental Committee for the Safeguarding of the Intangible Cultural Heritage. Paris: UNESCO. 